\title{
IMPACT OF MARKETING MIX STRATEGY ON COIMBATORE PRIVATE HOSPITALS PERFORMANCE MEASURED BY PATIENT SATISFACTION: AN EMPIRICAL STUDY
}

\author{
N. INBASAGARAN ${ }^{1} \&$ R. CHANDRASEKARAN ${ }^{2}$ \\ ${ }^{1}$ Research Scholar, Bharathiar University, Coimbatore, Tamil Nadu, India \\ ${ }^{2}$ Professor, Karunya School of Management, Coimbatore, Tamil Nadu, India
}

\begin{abstract}
Health care in India is one of the largest service sectors, with more than 4 million people engaged. The health care services in India, based upon various systems of medical practices such as Allopathy, Ayurveda, Unani, Siddha and Homeopathy. Among all the above, allopathy is the widely used medical practice. The infrastructure in the private sector provides at least 80 per cent of health services in the country and can be classified as private dispensaries, private hospitals, charity hospitals and corporate hospitals. The Indian health care industry is expanding at a phenomenal rate. Private hospitals, government investment and foreign aid in the public health programs appear to be driving this boom. More than 300 million strong middle class "health care consumers" are creating unforeseen demand for quality health care. In view of the recognition of the importance of marketing to the private hospitals worldwide, Indian private hospitals have started adopting marketing strategies to improve their performance in terms of profits and patient satisfaction. In the current scenario, marketing is evolving to become a full-fledged function and going beyond traditional marketing services. In view of this, this study is positioned to inquire the marketing strategies practiced by private hospitals and evaluate their effectiveness. Even though there are so many studies related to the marketing strategies in hospitals, services marketing in hospitals, service quality in hospitals and the patients view on services offered by hospitals, there is no exclusive study on the implementation of marketing strategies in hospitals at Coimbatore. Hence, the present study has made an attempt to fill up the research gap.

The present study will aim to find the gaps in the marketing strategy of private hospitals in Coimbatore and point out the need for introducing improvements in promotion of hospital services and patient satisfaction. Thereby, it helps management of private hospitals to take steps in the right direction to make their organizations viable and competitive.
\end{abstract}

KEYWORDS: Health Care Consumers, Health Services, Patient Satisfaction, Service Quality \& Hospital Services

Received: Aug 08, 2017; Accepted: Aug 28, 2017; Published: Sep 13, 2017; Paper Id.: IJBMROCT20173

\section{INTRODUCTION}

India is considered to have a good health care network available in both rural and urban areas of the country. The important component of the value chain in the Indian Healthcare industry rendering services is the hospital industry. A hospital is an institution for health care that provides treatment by specialized staff and equipment, and often, but not always provides for longer-term patient stays. The Indian health care delivery system compares favorably with many other Asian countries. This industry is growing at an annual rate of 14 per cent. The size of the Indian health care industry was estimated at Rs. 1, 717 billion (USD 359.85 million) ${ }^{1}$ and is projected to grow by 2012 to Rs. 3,163 billion (US $\$ 662.91$ million) at 13 per cent CAGR. The private sector dominates the 
healthcare market, accounting for nearly 80 per cent of the healthcare market, while public expenditure accounts for 20 per cent. $^{2}$

\section{Private Corporate Hospital in India}

Health care in India is one of the largest service sectors, with more than 4 million people engaged. The health care services in India, based upon various systems of medical practices such as Allopathy, Ayurveda, Unani, Siddha and Homeopathy. Among all the above, allopathy is the widely used medical practice. The infrastructure in the private sector provides at least 80 per cent of health services in the country and can be classified as private dispensaries, private hospitals, charity hospitals and corporate hospitals. The Indian health care industry is expanding at a phenomenal rate. Private hospitals, government investment and foreign aid in the public health programs appear to be driving this boom. More than 300 million strong middle class "health care consumers" are creating unforeseen demand for quality health care.

\section{Marketing Strategies and Performance of Hospitals}

The marketing strategies are useful to develop and sustain better health care relations for patients. Traditional doctor-patient relationships have been replaced by intermediary health organizations. The price transparency, quality health service, multi-specialty services, financial-accommodation, customer and competitor analysis and promotional measures are becoming more important in the globalized era, especially in the health care market (Reinhardt, 2006 ${ }^{3}$; Mahar, 2006) ${ }^{4}$. The marketing strategies of the corporate hospitals have been examined with the help of medical specialization, financial, accommodation, health packages, customer analysis, competitor analysis and promotional measures, which were identified

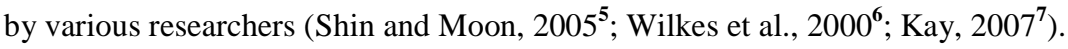

\section{Types of Marketing Strategies}

In the present study, the types of marketing strategies adopted by the private hospitals are measured by three important types, namely low price medium service (LPMS); high price excellent service (HPES) and medium price high service (MPHS).

\section{Process of Marketing Strategies in Hospitals}

A marketing strategy provides healthcare organizations with a shared vision of the future. All too often, an organization will perform a marketing task, send a direct mail shot, then sit back and see what happens. A strategic approach will ensure that organization maximizes returns on the marketing spending and boost the profits. The following is the process of marketing strategies adopted in hospitals 


\begin{tabular}{|c|c|c|}
\hline $\begin{array}{c}\text { Analysis of Patient } \\
\text { Groups }\end{array}$ & $\begin{array}{c}\text { Analysis of Hospital } \\
\text { Strengths and } \\
\text { Weaknesses }\end{array}$ & Marketing Strategies \\
\hline $\begin{array}{l}\text { Their characteristics } \\
\text { Their special needs } \\
\text { Medical realities of the } \\
\text { group } \\
\text { Where do they get their } \\
\text { needs served? } \\
\text { Competitors services, } \\
\text { how do patient group } \\
\text { feel } \\
\text { Areas of growth }\end{array}$ & $\begin{array}{l}\text { Performance and } \\
\text { economic analysis of } \\
\text { each service } \\
\text { Staff capabilities and } \\
\text { motivation } \\
\text { Characteristics of } \\
\text { other hospitals for } \\
\text { possible } \\
\text { collaborations } \\
\text { Future resource } \\
\text { availability } \\
\text { Stage of hospital as an } \\
\text { organization }\end{array}$ & $\begin{array}{l}\text { Survival } \\
\text { Strategies } \\
\text { Concentration } \\
\text { Strategies } \\
\text { Collaborative } \\
\text { Strategies }\end{array}$ \\
\hline
\end{tabular}

Figure 1: Process of Marketing Strategies Adopted in Hospitals

\section{Need for the Study}

The strategies hospitals use to compete provide significant insight into broader health care market developments because hospital strategy is shaped by a variety of external forces.

\section{Statement of the Problem}

The various factors that advocate the need for an indepth understanding of why marketing strategies are in the hospital industry is broadly classified under the following heads: Customer based factors and Environment based factors.

\section{The Research Rationale}

The research importance focus on that determinants and studying of factors affecting hospital performance are very important issue that help the hospital administration to properly improve patient satisfaction which leads to patient retention of health services in private sector hospitals. However, this research sought to overcome the limitations it encountered with the most methodologically sound techniques and it should be followed by other efforts in the same direction.

\section{OBJECTIVES OF THE PRESENT STUDY}

The objectives of the present study are confined to

- To reveal the profile of the hospitals and the rate of implementation of various marketing strategies in hospitals;

- To study the various determinants of the successful implementation of marketing strategies 
- And, its impact on the level of implementation of marketing strategies;

- $\quad$ To exhibit the profile of the patients;

- To measure the level of perception of service quality in hospitals among the patients;

- To examine the patients view on the various services offered by the hospitals, and

- To evaluate the impact of various marketing strategies on the level of perception of service

- Quality and services offered by hospitals.

\section{HYPOTHESES OF THE STUDY}

Based on the objectives of the study, the null hypotheses drawn from the study are:

- There is no significant difference between the big and small hospitals regarding the level of implementation of marketing strategies and also the view on determinants of successful implementation of marketing strategies.

- There is no significant impact of implementation of marketing strategies on the rate of implementation of marketing strategies in hospitals;

- There is no significant difference among the patients in big and small hospitals regarding their perception on service quality and services offered by hospitals;

- There is no significant association between the profile of the patients and their view on service quality and services offered by hospitals; and

- There is no significant impact of marketing strategies at the level of perception on service quality and services offered by hospitals.

\section{REVIEW OF LITERATURE}

The review of previous studies related to the implementation of marketing strategies in hospitals, its consequences, its determinants are summarized in this chapter.

Josm and Becker (2016) ${ }^{\mathbf{8}}$ indicated that a higher level of registered menses per had appears to image overall patient satisfaction. Conversely, hospitals with a higher proportion of nursing homes provided by contract nurses have significantly loan level patient satisfaction.

Savitha $(2016)^{9}$ found that the urban workers are having higher tendency to avail private health care services, whereas the rural prefer the public health care services. The quality of health care services play an important role in choosing the type of health facilities by the workers.

Kotler, et al., (2008) ${ }^{\mathbf{1 0}}$ noted that modern marketers focus on the customer rather than product and services, and believe din a stable, constant relationship with the customer, because they attempt to obtain the highest level of satisfaction and create value for the customer.

Bahadori et al., (2015) ${ }^{\mathbf{1 1}}$ identified six important factors that contribute to patient's choices of a clinic. These are the facilities and physical assets, physicians and employees, location and placement, services, prices and promotion. The most significant contributing factors to attract patients are 'physicians and employees' and the clinic environment. 
Sivakumar (2014) ${ }^{\mathbf{1 2}}$ concluded that the significantly and positively influencing variables in marketing strategy on the overall attitude towards hospitals are medical specialization, financial accommodation, customer analysis, competitor analysis of promotional measures. In the case of corporate hospitals, these variables are medical specialization, financial, accommodation, customer analysis, competitor analysis and promotional measures, whereas in the case of small hospitals, these variables are financial accomodation, health packages, customer analysis and promotional measures.

Reynolds (2013) ${ }^{\mathbf{1 3}}$ stated that the private hospitals provide more flexibility in their offering can provide as 'demanded' services at any time, targeted to different patient groups and can offer more levels of quality provision defining trust and commitment.

Berendas et al., $(2011)^{\mathbf{1 4}}$ revealed that private hospitals appeal to those in society who can afford and want to make choices about their health provision and can personally pay for health assessment and treatment.

\section{Research Gap}

Even though there are so many studies related to the marketing strategies in hospitals, services marketing in hospitals, service quality in hospitals and the patients view on services offered by hospitals, there is no exclusive study on the implementation of marketing strategies in hospitals at Coimbatore. Hence, the present study has made an attempt to fill up the research gap.

\section{Research Model}

The proposed research model consist of concepts, namely marketing strategies, determinants of successful implementation of marketing strategies, service quality and services offered by hospitals. The above said four concepts are measured with the help of variables drawn from reviews. In total there are seven 'Ps' in the services marketing mix along with the new marketing mixes in the health care sector (Valarie et al., 2006 ${ }^{\mathbf{1 5}}$ ). These are shown in the given figure

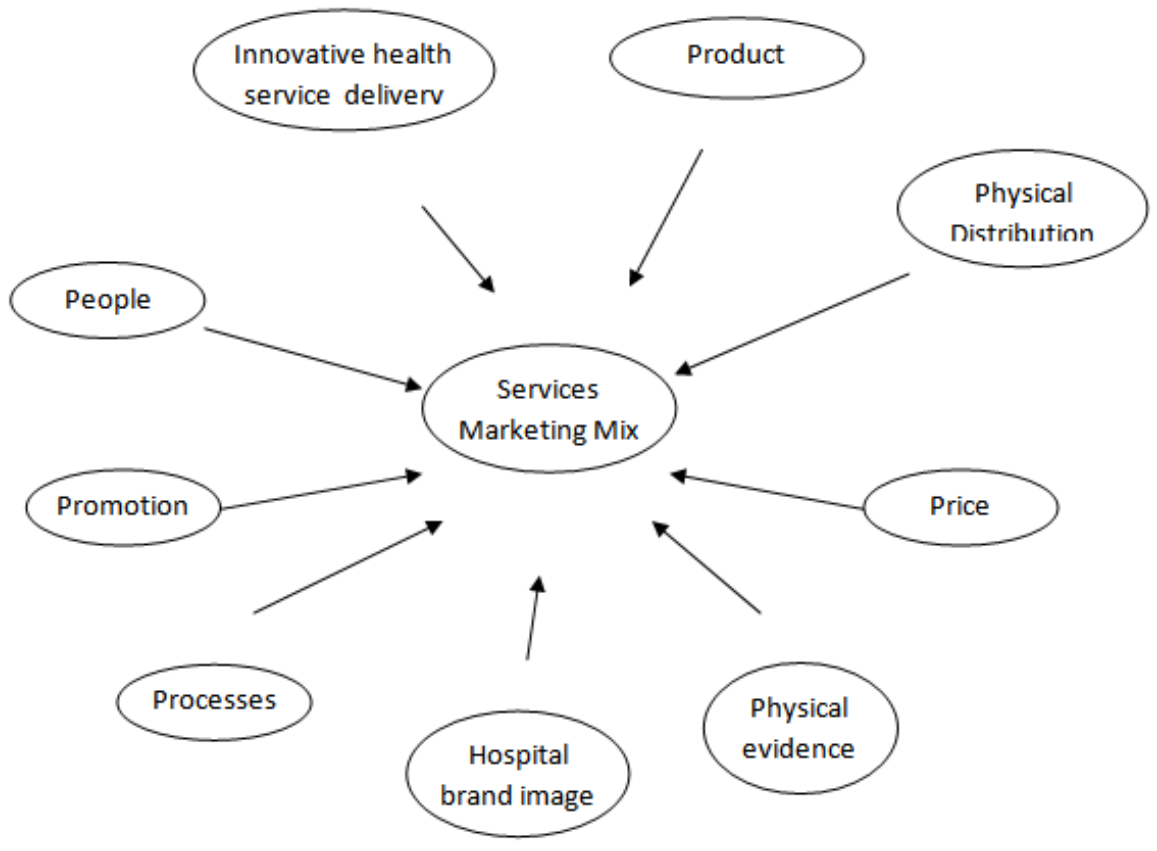

Figure 2: Marketing Mix in Health Care Sector 
Services marketing involves three main important activities, namely external marketing, internal marketing and interactive marketing (Bitner, et al., 1994 ${ }^{\mathbf{1 6}}$ ). The level of activities involved in it is setting the promise, enabling the promise and delivering the promise (Bitner, et al., $1990^{\mathbf{1 7}}$ ). The marketers should consider above said three important activities in their strategy formulation (Bitner, $1995^{\mathbf{1 8}}$ ).

The important aspects in hospitals have been identified by (Strasser, et al., 1995) ${ }^{\mathbf{1 9}}$; and (Daniel et al., 1996) ${ }^{\mathbf{2 0}}$, These are related to physician behavior, supporting staff behavior and the internal environment at hospitals.

In the present study the included discussion is presented in the given figure.

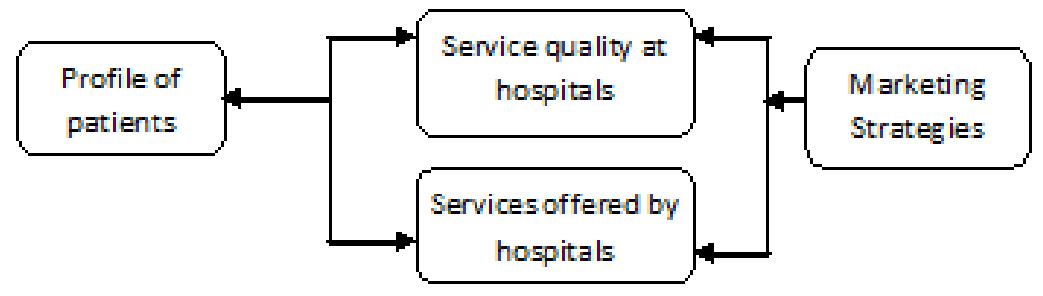

Figure 3: Hospital Marketing Strategies

The impact of implementation of marketing strategies on the perception on service quality and services offered by the hospital is examined in big, small hospitals separately and also for pooled data.

\section{RESEARCH METHODOLOGY}

The research methodology deals with the research methods and the selection of various research methods which are appropriate for the research study. It starts from the collection of reviews to report preparation. The methodology includes the research design, sampling framework, data collection, framework of analysis and limitations of the study.

\section{Research Design of the Study}

The applied research design is 'descriptive and diagnostic' research design.

\section{Sampling Plan of the Study}

The proportionate sampling was adopted to distribute the total sample size of 160 among the population of 206 hospitals. The sample random sampling method (lottery method) was adopted to select the samples in each group and the results were Big hospitals was 57 and Small hospitals was 103.

\section{Selection of Patients from Hospitals}

The snowball sampling method was adopted to select the patient from hospital. From each hospital, 3 patients were identified with the help of relevant medical officers in the hospitals. Hence, the total number of patients from big and small hospital came to 171 and 309 patients respectively.

\section{Data Collection}

Since the present study is completely based on the primary data, a special care was taken to design the structured questionnaire and interview schedule. One is meant for medical officer, whereas another is meant for patients in hospitals. The relevant variables related to the concepts generated for the study were drawn from the review of previous studies. A pilot study was conducted among 20 hospitals, domestic and 40 patients. Based on their feedback, certain additions, 
deletions and modifications were carried out to prepare the final interview schedules.

\section{Framework of Analysis}

The following statistical tools: T-test, one-way analysis of variance, exploratory factor analysis, multiple regression analysis, discriminate analysis, confirmatory factor analysis (CFA) have been administered to analyze the data.

\section{LIMITATIONS OF THE STUDY}

The present study is subjected to certain limitations. To name a few: the present study is confined to its scope to Coimbatore City only, even though the sample size is determined by the scientific way, the applied sampling procedure is unscientific, only service marketing mix strategies are included as the marketing strategies for the present study.

\section{Summary of Findings}

The impact of marketing strategy implementations on the service quality in the big and the small hospitals and the pooled data have been computed separately. The results are given in Table 1

Table 1: Impact of Marketing Strategies on the Service Quality of Hospitals

\begin{tabular}{|c|l|c|c|c|}
\hline \multirow{2}{*}{ Sl. No. } & \multicolumn{1}{|c|}{ Marketing Strategies } & \multicolumn{3}{c|}{ Regression Coefficient in Hospitals } \\
\cline { 3 - 5 } & & Big Hospital & Small Hospital & Pooled \\
\hline 1. & Product & $0.1443^{*}$ & 0.1091 & $0.1234^{*}$ \\
\hline 2. & Price & 0.1011 & $0.1343^{*}$ & 0.1699 \\
\hline 3. & Place & 0.0894 & $0.1414^{*}$ & 0.1094 \\
\hline 4. & Promotion & $0.1641^{*}$ & 0.0834 & $0.1234^{*}$ \\
\hline 5. & People & $0.2269^{*}$ & 0.1023 & $0.1804^{*}$ \\
\hline 6. & Process & $0.2145^{*}$ & $0.1266^{*}$ & $0.1732^{*}$ \\
\hline 7. & Physical Evidence & -0.0542 & -0.0433 & -0.0613 \\
\hline 8. & Innovative Health Score Delivery & $0.2664^{*}$ & $0.1249^{*}$ & $0.2089^{*}$ \\
\hline 9. & Hospital brand image & $0.2554^{*}$ & $0.1408^{*}$ & $0.1869^{*}$ \\
\hline & Constant & 1.0334 & 0.7244 & 0.9149 \\
\hline & R & 0.7987 & 0.7173 & 0.8403 \\
\hline & F-statistics & $9.0413^{*}$ & $8.0886^{*}$ & $13.9045^{*}$ \\
\hline
\end{tabular}

* Significant at the five per cent level.

The significantly influencing marketing strategies on the overall service quality in the big hospitals are their product, promotion, people, process, innovative health service delivery and hospital brand image strategies since their respective regression coefficients are significant at the five per cent level.

The impact of implementation of marketing strategies on the overall attitude towards hospitals in the big and the small hospitals and also for pooled data has been computed separately. The results are given in Table 2.

Table 2: Impact of Marketing Strategies on the Overall Attitude towards Hospitals

\begin{tabular}{|c|l|c|c|c|}
\hline \multirow{2}{*}{ Sl. No. } & \multicolumn{1}{|c|}{ Marketing Strategies } & \multicolumn{3}{|c|}{ Regression Coefficient in Hospitals } \\
\cline { 3 - 5 } & & Big Hospital & Small Hospital & Pooled \\
\hline 1. & Product & $0.2146^{*}$ & 0.1088 & $0.1691^{*}$ \\
\hline 2. & Price & $0.1542^{*}$ & 0.0996 & 0.1344 \\
\hline 3. & Place & 0.1024 & $0.1624^{*}$ & $0.1403^{*}$ \\
\hline 4. & Promotion & 0.1142 & 0.0884 & 0.1045 \\
\hline 5. & People & $0.1335^{*}$ & 0.1334 & $0.1304^{*}$ \\
\hline 6. & Process & $0.1342^{*}$ & 0.0454 & 0.0886 \\
\hline 7. & Physical Evidence & $0.1446^{*}$ & $0.1249^{*}$ & $0.1311^{*}$ \\
\hline 8. & Innovative Health Score Delivery & $0.1737^{*}$ & $0.1244^{*}$ & $0.1367^{*}$ \\
\hline
\end{tabular}




\begin{tabular}{|c|l|c|c|c|}
\hline \multicolumn{5}{|c|}{ Table 2: Contd., } \\
\hline 9. & Hospital brand image & $0.1669^{*}$ & $0.1341^{*}$ & $0.1504^{*}$ \\
\hline & Constant & 1.0989 & 0.7337 & 1.0478 \\
\hline & $\mathrm{R}^{2}$ & 0.7814 & 0.7306 & 0.8342 \\
\hline & F-statistics & $9.3942^{*}$ & $8.6434^{*}$ & $10.0865^{*}$ \\
\hline
\end{tabular}

* Significant at the five per cent level.

The significantly influencing marketing strategies on the overall attitude towards hospitals in the big hospitals are their product, price, people, process, physical evidence, innovative health service delivery and hospital brand image since their respective regression coefficients are significant at the five per cent level.

\section{CONCLUSIONS}

The present study concludes that the rate of implementation of marketing strategies in big hospitals is higher compared to smaller hospitals. The big hospitals are very sword in the innovative health service delivery and brand building. The important determinants of the successful implementation of marketing strategies at the hospital are interactive and internal marketing. The highly influencing marketing strategies at the level of perception of service and service quality in hospital patients are among the innovative health service delivery and brand building. Hence the present study concludes the need of appropriate marketing strategy in various customer segments in order to satisfy all types of customers in the health care industry in order to create the patient loyalty towards the hospital. Since the patients are expecting updated medical treatment in all fields, the hospitals have to provide to its to retain the existing patients and also to attract new patients.

\section{SUGGESTION}

Need for updated marketing plan, appropriate product mix, marketing through public relations, medical specialization, social touch, brand building exercises, mergers and amalgamations, use of search engine optimization and marketing for the hospital website with an emphasis on services and location, use of relevant digital content about health conditions, use of social media marketing strategy to the hospital's full advantage, keep patients on track with personalized hospital communication.

\section{SCOPE FOR FUTURE RESEARCH}

The present study provides a base for so many future research works. In future, there may be a comparative study on the implementation of marketing strategies by corporate and non-corporate hospitals. The scope of the present study may be needed for a separate study on the difficulties in the formulation and implementation of marketing strategies in the healthcare industry.

\section{REFERENCES}

1. Currency Exchange Rates, all refer to 1 US\$=47.7133 as on May 26, 2010.

2. www.cygnusindia.com/viewelatestreports.asp.accessed 7 Feb 2009.

3. Reinhardt, U., (2006), "The Pricing of US Hospital Services: Chaos Behind a Veil of Secrecy”, Health Affairs, 25 (1), pp. $57-$ 69.

4. Mahar, M., (2000), “Money Driven Medicine”, Harper Collins, New York, NY.

5. Shin, J and Moon, S., (2005), "Direct-to-Consumer Prescription Drug Advertising: Concerns and Consumer's Benefit”, The 
Impact of Marketing Mix Strategy on Coimbatore Private Hospitals

Journal of Consumer Marketing, 22 (7), pp. 397-403.

6. Wilkes, M., Bell, R. And Kravitz, R.C., (2000), "Direct-to-Consumer Prescription Drug Advertising: Trends, Impact and Implications", Health Affairs, 20 (2), pp. 110-128.

7. Kay, M.J (2007), “Healthcare Marketing: What is Salient?”, International Journal of Pharmaceutical and Health Care Marketing, 1 (3), pp. 247-263.

8. Chasm, M., Hockenberry and Edward R. Becher, (2016), "How do hospital nurse staffing strategies affect patient satisfaction”, ILR Review, 69 (4), pp. 890-910.

9. Savitha, N., (2016), "Factors determining the choice of Heath Care of Textile and engineering, industrial whereas in Coimbatore”, International Journal of Innovation and Economic Development, 1 (6), pp. 7-18.

10. Kotler, P., Show Louitz, J., Stevars, R., (2008), "Strategies marketing for health care organizations: building a customer driven health system" United State of America: Jossey-Bass, pp. 9-12.

11. MohanmadhariumBahadori, EhsonTeymonzadeh, RaminDavangard, Alinaim, Mehdi Readabadi, Kahlil, A., (2015), “Factors Contributing towards patient choice of a hospital, clinic from the patients and managers' perspective”, Electronic Physician, 8(5), pp. 2378-2387.

12. Sivakumar, M., (2014), “Assessment of Service Quality in Multi Speciality Hospitals with reference to Madurai”, International Journal of Business and Administration Research Review, 1 (6), pp. 170-174.

13. Reynolds, J., (2013), "A literature review: the role of the private sector in the production of nurses in India, Kenya, South Africa and Thailand", Human Resources for Health, 11 (14), pp. 11-14.

14. Berendes, S., Heywood, P., Oliver, S., Garmer, P., (2011), "Quality of private and public condolatory health care in low and middle income countries: Systematic review of comparative studies”, PLOS Medicine, 8(1), pp.11-13.

15. Valarie A. Zeithaml, Mary Jo Bitner and Dwayne D. Greinler (2006) Services Marketing: Integrating Customer Focus Across the Firm, $4^{\text {th }}$ Edition, Bun Ridge, IL: Irwin-McGraw-Hill.

16. Bitner, M.J., Broms, B.H., Mohr, L.A., (1994), "Critical Service Encunters: The Employees View Point”, Journal of Marketing, 58 (2), pp. 95-106.

17. Bitner, M.J., Booms, B.H., Tetreault, M.S. (1990), “The Service Encounter: Diagnosing Favorable and Unfavorable Incidents", Journal of Marketing, 54 (2), pp. 71-84.

18. Bitner, M.U. (1995), “Building Service Relationships: It's all about Promises”, Journal of the Marketing Science, 23 (6), pp. 246-251.

19. Strasser, S., Schweikhart, S., Welch, G.E and Burge, J.C (1995), "Satisfaction with Medical Care”, Journal of Health Care Marketing, 15 (3), pp. 34-43.

20. Daniel Butler, Sharon L. Oswald and Douglas E. Tinner (1996), "The Effects of Demographics of an Determinants of Perceived Health care Service Quality”, Journal of Management in Medicine, 10(6), pp.8-20. 
